\title{
Sucesso Social, Branqueamento e Racismo ${ }^{1}$

\author{
Marcus Eugênio O. Lima² \\ Universidade Federal da Bahia \\ Jorge Vala \\ Instituto Superior de Ciências do Trabalho e da Empresa - Lisboa
}

\begin{abstract}
RESUMO - Este estudo investiga os efeitos da cor da pele percebida e do sucesso social no branqueamento e na infra-humanização. Para a consecução deste objetivo, indivíduos brancos deveriam avaliar um grupo de pessoas negras e um grupo de pessoas brancas (representados por fotografias), que obtinham sucesso social ou que eram mal sucedidos socialmente. $\mathrm{O}$ delineamento utilizado continha duas variáveis independentes inter-participantes (cor da pele: brancos versus negros) e desempenho social (sucesso versus fracasso). Os resultados indicaram que os negros que obtêm sucesso social são percebidos como mais brancos do que os negros que fracassam. Uma análise de mediação indicou que quanto mais os negros com sucesso são percebidos como brancos mais características tipicamente humanas lhes são atribuídas. O inverso se passa para os negros mais percebidos como negros. Estes resultados são analisados e discutidos à luz das teorias sobre racismo no Brasil e sobre as novas expressões de racismo.
\end{abstract}

Palavras-chave: sucesso; branqueamento; racismo e infra-humanização.

\section{Social Success, Whitening and Racism}

\begin{abstract}
This study investigates the effects of perceived skin colour and of the social success on the whitening and on the infra-humanization. In this sense, white subjects evaluated a group of black people or a group of white people (represented by photographs), which obtained social success or that fail. The design contains two between subject's independent variables (white versus black) and social performance (success versus failure). The results indicate that blacks that obtain social success are perceived as whitener than the blacks that fail. A mediation analysis indicated that as much the blacks with success are whitened, more typically human characteristics are attributed to them. The inverse happens for blacks less whitened. These results are analysed and discussed in according to the theories about racism in Brazil and the new expressions of racism.
\end{abstract}

Key words: success; whitening; racism and infra-humanization.

Vários estudos têm demonstrado que o racismo, nas atuais sociedades formalmente democráticas e ciosas com o "politicamente correto", tem mudado as suas formas de expressão, no sentido de se tornarem progressivamente mais disfarçadas ou veladas. Na Europa e nos EUA, tem-se falado em novas expressões do racismo e novas teorias sobre este tema têm surgido na psicologia social, a exemplo das teorias do racismo simbólico e moderno (Kinder \& Sears, 1981; McConahay \& Hough, 1976), do racismo aversivo (Gaertner \& Dovidio, 1986), do racismo ambivalente (Katz \& Hass, 1988) e do racismo sutil (Pettigrew \& Meertens, 1995; Vala, Brito \& Lopes, 1999). No Brasil, alguns estudos têm analisado estas modernas expressões mais veladas de racismo (Camino, Silva, Machado \& Pereira, 2001; Lima, 2003; Turra \& Venturi, 1995).

Comum a todas estas novas formas de expressão do racismo é, por um lado, a preocupação em não ferir frontalmente a norma anti-racista e assim ameaçar a auto-imagem de pessoa igualitária dos indivíduos e, por outro lado, a possibilidade

1 Os autores agradecem aos professores Dalila Xavier de França (Universidade Federal de Sergipe) e Cícero R. Pereira (Universidade Católica de Goiás) pelas valiosas sugestões. Este trabalho é uma versão de um dos capítulos da Tese de Doutorado do primeiro autor, sob a orientação do segundo, defendida no Instituto Superior de Ciências do Trabalho e da Empresa (Portugal).

2 Endereço: Rua Atalaia, 260 ap. 103 Atalaia, Aracaju, SE, Brasil 49035110. E-mail: meolima@uol.com.br. destas expressões aparentemente menos violentas transformarem-se em manifestações flagrantemente agressivas, quando exista um contexto social, econômico e político que as legitime e justifique. Específico a cada uma dessas novas formas de expressão do racismo é o seu caráter cultural e histórico, que reflete as vicissitudes das relações "interracializadas" de cada contexto social onde emergem.

É neste sentido que as novas expressões do racismo no Brasil carregam em si alguns elementos comuns e outros elementos diferenciados das expressões do racismo na Europa e nos EUA. Considerando o racismo como um processo de hierarquização, exclusão e discriminação contra um indivíduo (ou toda uma categoria social), que é definido como diferente com base em alguma marca física externa (real ou imaginária), a qual é re-significada em termos de uma marca cultural interna que supostamente define padrões de comportamento (Lima, 2003), hipotetizamos que um dos elementos de expressão do racismo é a infra-humanização das vítimas, as quais são percebidas como possuindo mais características naturais ou naturalizadas do que culturais. Neste sentido, os grupos racializados (por exemplo, negros) são aproximados do pólo da natureza e distanciados do pólo da cultura em relação aos grupos não "racializados" (por exemplo, brancos).

Um dos elementos importantes que distingue as expressões do racismo no Brasil das expressões em sociedades "bi-raciais", como a norte-americana, ou em sociedades onde 
o racismo se dirige a grupos exógenos ou assim percebidos, como as européias, é o branqueamento ${ }^{3}$. Nesse estudo, procuramos analisar as novas expressões de racismo no Brasil, considerando a performance social como uma variável que atua sobre o branqueamento e sobre a infra-humanização dos negros.

\section{A "essência humana" e as formas de infra- humanização}

A infra-humanização resulta da negação a membros de outros grupos ("exogrupos") de determinadas características tipicamente humanas, características que compõem a "essência humana". Mas que características definem a "essência humana"? Vários estudos têm apontado como características tipicamente humanas são os valores (Schwartz \& Struch, 1989); a cultura (Moscovici \& Pérez, 1999); a linguagem, a inteligência e a capacidade de expressar sentimentos (Leyens \& cols., 2000). Daniel Bar-Tal (1989) foi um dos pioneiros na análise da infra-humanização dos grupos minoritários, ao analisar o modo como judeus eram percebidos pelo regime nazista e afirmar que a infra-humanização pode ocorrer através da "deslegitimação" da categoria ou grupo social com a atribuição de características extremamente negativas:

Dehumanization involves categorizing a group as inhuman either by using categories of subhuman creatures such as inferior races and animals, or by using categories of negatively valued superhuman creatures such demons, monsters, and satans. Trait characterization is done by using traits that are evaluated as extremely negative and unacceptable to a given society (Bar-Tal, 1989, p. 93).

Mais tarde, a infra-humanização foi analisada em estudos empíricos na psicologia social, em diversas perspectivas de análise. De uma maneira mais específica, os principais indicadores de infra-humanização utilizados nos estudos na psicologia social são: a) a negação da capacidade do "exogrupo" de adotar valores tipicamente humanos, b) a caracterização de "exogrupo"s através de traços de natureza em oposição aos traços de cultura e c) a sub-atribuição de sentimentos ao "exogrupo".

Struch e Schwartz (1989) conceptualizaram a infrahumanização do "exogrupo" em dois níveis: a) ao nível da diferenciação dos valores, no sentido de que quanto maior a percepção de que o "exogrupo" adota valores diferentes do "endogrupo", maior é a infra-humanização e b) ao nível da capacidade de expressar valores tipicamente humanos, tais como, a consideração e a compaixão pelos outros; a preocupação com o bem-estar de toda a sociedade e a educação humanitária das crianças. Esses autores realizaram um estudo

3 Embora neste trabalho estejamos interessados no papel fundamental que o branqueamento desempenha nas expressões de racismo no Brasil, não ignoramos a importância de outros elementos também fundamentais, tais como, o mito da democracia racial e o culto à mestiçagem. A este respeito são referenciais os trabalhos de Gilberto Freyre (1933/1987), Florestan Fernandes (1966), Lilia Schwarcz (1993, 1996), Kabengele Munanga (1996), Darci Ribeiro (1996), dentre outros. junto a uma amostra de israelenses, que deveriam indicar os seus níveis de identificação com o seu próprio grupo e os valores que estimavam. Em seguida, os participantes deveriam avaliar um grupo de Judeus ultra-ortodoxos. Os resultados indicaram que os dois indicadores de infra-humanização apresentaram-se positivamente relacionados com a disposição para a agressão contra o "exogrupo".

A infra-humanização pode ser analisada também ao nível de uma atribuição diferenciada a membros do próprio grupo ("endogrupo") e do outro grupo da capacidade de expressão de sentimentos e emoções primárias (Leyens \& cols., 2000). Estas emoções são definidas pelos autores como características que são compartilhadas por seres humanos e também por animais. Exemplos de emoções primárias são a raiva, o medo, a surpresa e o prazer. As emoções secundárias ou sentimentos, por sua vez, são unicamente humanas. Exemplos de sentimentos são o amor, a resignação, a esperança, o arrependimento, etc. Leyens e cols. realizaram um conjunto de estudos para verificar o papel da atribuição de emoções primárias e sentimentos na infra-humanização dos "exogrupos".

Os autores verificaram que são atribuídas menos emoções secundárias ou sentimentos aos membros do "exogrupo" do que aos membros do "endogrupo", não havendo diferenças ao nível das emoções primárias (Leyens \& cols., 2001).

Moscovici e Pérez (1999) argumentam que as representações sociais construídas sobre os grupos "racializados" podem estruturar-se em dois eixos: o eixo dos traços de natureza e o eixo dos traços de cultura. Os traços "naturais" são definidos como características que são usadas de maneira indiferenciada nas descrições de seres humanos e nas descrições de animais. Já os traços "culturais" são aqueles típicos dos seres humanos (Moscovici \& Pérez, 1997). Para testar esta hipótese, Moscovici e Pérez (1999, experimento 1) realizaram um estudo sobre as representações sociais construídas acerca dos ciganos na Espanha. Os participantes do estudo, espanhóis não ciganos, liam um texto sobre as estratégias utilizadas ao longo da história para assimilar os ciganos à sociedade dominante. Metade dos participantes foi informada de que os ciganos aceitaram estas estratégias e se deixaram integrar culturalmente. A outra metade foi informada de que os ciganos não aceitaram a integração cultural. Em seguida, os participantes deveriam descrever os ciganos com base numa lista de adjetivos "naturais positivos" (intuitivo, livre, fisicamente hábil, espontâneo e com ritmo musical), "naturais negativos" (selvagem, impulsivo, agressivo, visceral e ruidoso), "culturais positivos" (criativo, leal à sua identidade, solidário, mentalmente habilidoso e extrovertido) e "culturais negativos" (vingativo, perverso, manipulador, falso ou mentiroso e mal-intencionado). Moscovici e Pérez (1999) verificaram que os ciganos que recusaram a integração cultural foram mais descritos em termos de traços naturais do que os ciganos que se deixaram integrar. Em um segundo experimento, os autores confirmaram os resultados verificados no primeiro.

Correia, Brito, Vala e Pérez (2001) utilizaram os mesmos traços naturais e culturais do estudo original de Moscovici e Pérez (1999), e verificaram que, em Portugal, são atribuídos mais traços naturais negativos do que naturais positivos na descrição dos ciganos. Na França e em países do Leste 
europeu (Romênia, Moldávia e Bulgária), os ciganos são representados mais em termos de traços naturais do que em termos de traços culturais.

Embora estes indicadores de racismo e infra-humanização tenham se mostrado importantes nos estudos referidos, nenhum estudo realizado no Brasil utilizou a atribuição diferenciada de características culturais e naturais aos negros como um indicador de racismo.

\section{Branqueamento e racismo no Brasil}

Vários estudiosos do racismo no Brasil têm demonstrado que existe uma forte relação entre o fracasso social e econômico com a cor negra e entre sucesso e a cor branca (Adorno, 1996; Degler, 1971; Guimarães, 1999). Tanto que o branqueamento parece ser o elemento principal que diferencia o racismo brasileiro de outros racismos (Skidmore, 1989). De fato, o racismo no Brasil manifesta-se, entre outros aspectos, pelo branqueamento dos indivíduos que fazem sucesso e o enegrecimento ou empardecimento dos que fracassam. Adorno (1996), analisando boletins de ocorrências de "crimes violentos" em São Paulo no ano de 1990, observou que a depender do curso do processo, o réu pode mudar de cor. Se for sendo progressivamente inocentado pelas evidências pode se tornar branco ou moreno claro nas descrições feitas. Por outro lado, se as evidências apontarem para a sua culpabilidade pode se tornar moreno escuro ou negro.

No Brasil, como demonstraram os estudos de Adorno (1996) e a análise sociológica de Degler (1971), é o branqueamento da condição social do negro que define o racismo e a infra-humanização contra ele. Sendo assim, podemos supor que os efeitos da cor da pele e do sucesso na infrahumanização dos grupos podem ser mediados pelo branqueamento. Não obstante a importância do branqueamento nas relações "racializadas" no Brasil, nenhum estudo analisou empiricamente o papel do branqueamento como mediador das expressões de racismo ${ }^{4}$.

Assim sendo, realizamos dois estudos com o objetivo de analisar a relação entre a cor da pele dos grupos, o seu desempenho ou performance social, o modo como a sua cor da pele é percebida (branqueamento) e a infra-humanização dos grupos. O primeiro estudo teve como objetivo validar a distinção entre traços naturais e traços culturais, bem como, o papel de infra-humanização refletido nessa forma de representação social dos grupos. O segundo estudo analisou o papel da cor da pele dos grupos e da sua performance social no branqueamento e na atribuição desses traços de natureza e de cultura.

\section{Estudo 1}

Seguindo os pressupostos de Moscovici e Pérez (1999), procedemos a uma validação global da distinção entre tra-

4 Neste trabalho entendemos o termo mediador e mediação num sentido estritamente estatístico. Um mediador é uma variável que interfere na relação entre uma variável antecedente e uma variável critério; tornando, quando presente na relação, o poder da primeira nulo (mediação perfeita) ou mais fraco. É neste sentido que o branqueamento pode ser concebido como um mediador da relação entre a cor da pele das pessoas e o racismo expresso contra elas. ços de natureza e traços de cultura. O objetivo deste estudo foi verificar se existe uma representação diferenciada entre características exclusivamente humanas, e portanto mais flexíveis e aprendidas ao longo da vida, e características que são utilizadas igualmente para descrever seres humanos e animais. As primeiras características, mais flexíveis e aprendidas, são aqui denominadas "características culturais". As últimas características, menos flexíveis, são denominadas "características naturais".

Realizamos um estudo junto a uma amostra de 114 universitários, de ambos os sexos, aos quais perguntávamos em que medida cada característica descrevia exclusivamente seres humanos ou descrevia exclusivamente animais. Foi utilizado um questionário, composto por oito questões, sendo as seis primeiras relativas à validação da distinção, a $7^{\mathrm{a}}$ era um controle do carácter estereotípico dos traços e a $8^{\mathrm{a}}$ referia-se à valência do traço.

Primeiramente, compusemos as dimensões de "traços de natureza" e de "traços de cultura", considerando os resultados da primeira questão. Na primeira questão os participantes deveriam indicar em que medida cada um dos 12 traços caracterizavam seres humanos e em que medida caracterizavam animais. Utilizamos uma escala bi-polar de seis posições, que variava de 1 (caracteriza exclusivamente os animais) a 6 (caracteriza exclusivamente os seres humanos), sendo 4,5 o ponto intermediário entre o "caracteriza mais os seres humanos do que os animais" (4) e o "caracteriza quase exclusivamente seres humanos" (5). Em seguida, realizamos um teste $t$, tomando como parâmetro o ponto intermediário $(4,5)$. As médias superiores a 4,5 refletem a percepção de que o traço caracteriza quase exclusivamente seres humanos, respostas inferiores refletem a percepção de que o traço caracteriza mais aos animais do que aos seres humanos ou igualmente a estas duas categorias. Como podemos ver na Tabela 1, dos 12 adjetivos, cinco são significativamente percebidos como estando do lado da natureza (esperto, espontâneo, agressivo, descontrolado ${ }^{5}$ e impulsivo). O traço "alegre", teoricamente considerado na dimensão de natureza, não se diferenciou do ponto médio. Todavia, manteremos este traço na dimensão dos traços naturais, uma vez que, de acordo com as avaliações dos participantes, ele não pode ser considerado como exclusivamente humano. Dentre os 12 adjetivos, cinco foram percebidos como apropriados quase ou exclusivamente para caracterizar seres humanos (progressista, sábio, falso ou mentiroso, infantil e ignorante). $\mathrm{O}$ traço inteligente, embora não tenha sido colocado como exclusivo desta dimensão, será considerado neste estudo como atributo tipicamente humano; uma vez que, como indicam um conjunto de estudos realizados por Leyens e cols. (2000), a inteligência é característica mais referida para diferenciar os seres humanos dos animais.

Foram então compostas as dimensões de representação dos grupos (cultura versus natureza). Em seguida, analisamos os valores de cada uma das dimensões nos quatro indicadores de infra-humanização de que dispúnhamos (típicos de pessoas, típicos de animais, herdado versus apreendido e idade de expressão da característica). Os resultados obtidos indicaram que os traços culturais são mais percebidos como típicos de pessoas do que de animais, aprendidos do que herdados e

5 Este traço é significativo num teste unilateral (one-tailed). 
Tabela 1. Médias dos traços utilizados para descrever seres humanos ou animais e testes $t$ de Student (two-tailed) utilizando o ponto médio como critério (4.5) $(\mathrm{N}=114)$

\begin{tabular}{lccc}
\hline Traço & Média & $\begin{array}{c}\text { Desvio } \\
\text { padrão }\end{array}$ & Testes t \\
\hline Inteligente & 4,58 & 0,87 & $t(103)=0,90$ ns. \\
Progressista & 5,34 & 0,83 & $t(97)=0,49 p<0,001$ \\
Sábio & 5,46 & 0,76 & $t(99)=12,67 p<0,001$ \\
Ignorante & 4,59 & 1,28 & $t(107)=0,75 n s$. \\
Falso ou Mentiroso & 5,80 & 0,48 & $t(103)=27,54 p<0,001$ \\
Infantil & 4,93 & 0,92 & $t(97)=4,73 p<0,001$ \\
Esperto & 3,37 & 0,92 & $t(105)=-12,56 p<0,001$ \\
Alegre & 4,56 & 0,99 & $t(99)=0,61$ ns. \\
Espontâneo & 3,95 & 1,36 & $t(97)=-3,93 p<0,001$ \\
Agressivo & 3,80 & 0,71 & $t(91)=-9,34 p<0,001$ \\
Descontrolado & 4,32 & 1,09 & $t(99)=-1,65 p=0,10$ \\
Impulsivo & 3,90 & 1,16 & $t(105)=-5,28 p<0,001$ \\
\hline
\end{tabular}

Nota: a escala varia de 1-caracteriza exclusivamente animais a 6-caracteriza exclusivamente seres humanos.

são expressos em idades mais adultas do que na infância. O contrário se passa para os traços naturais.

Tendo validado a distinção entre traços naturais e culturais, procedemos ao controle da valência dessas dimensões. Para este fim, utilizamos uma questão sobre a positividade ou negatividade de cada característica. Os participantes deveriam indicar em que medida cada característica era positiva ou negativa, numa escala que variava de 1 (totalmente negativo) a 5 (totalmente positivo). Os resultados indicaram que a dimensão dos traços de cultura positivos (inteligentes, sábios e progressistas, $M=4,54$ ) não se diferencia da dimensão dos traços de natureza positivos (alegres, espertos e espontâneos, $M=4,56), t(111)=-0,12 n s$. Também os traços de cultura negativos (falsos, ignorantes e infantis, $M=2,27)$ não se diferenciaram dos traços de natureza negativos (agressivos, descontrolados e impulsivos, $M=2,35), t(109)=-1,19 n s$. Os traços positivos considerados conjuntamente se diferenciaram significativamente dos traços negativos $(M=4,55$ versus $M=2,04, t(109)=32,77$, $p<0,0001)$. Da mesma forma, e de acordo com os pressupostos desta distinção, os traços de cultura não se diferenciaram dos de natureza, ao nível da valência, ( $M=3,27$ versus $M=3,32, t(109)=-0,83 n s)$.

Este primeiro estudo teve como objetivo validar uma diferenciação entre características culturais e características naturais. A importância da validação dessa diferenciação no Brasil se prende a dois fatores: a) a necessidade de desenvolver técnicas de estudo do racismo que não impliquem na obstrução de respostas, ou seja, que sejam menos susceptíveis às influências das normas anti-racistas e do "politicamente correto"; b) a possibilidade de analisar o racismo como um processo de infra-humanização do outro, o que consideramos torna mais amplo o conceito de racismo, por implicar além da discriminação e da segregação sociais, a segregação simbólica.

\section{Estudo 2}

Num segundo estudo, procuramos entender o papel desempenhado pela cor da pele dos grupos (brancos versus negros), pela sua performance social (sucesso versus fracasso) no modo como são percebidos (branqueamento) e na atribuição diferenciada de características naturais e culturais (infra-humanização). As nossas principais hipóteses de trabalho são:

a) serão atribuídas mais características culturais aos brancos do que aos negros;

b) serão atribuídas mais características culturais aos grupos que obtêm sucesso do que aos que fracassam socialmente;

c) os grupos com sucesso serão percebidos como mais brancos do que os grupos que fracassam;

d) o branqueamento atuará como um mediador entre a cor da pele percebida dos grupos e as avaliações feitas sobre eles.

\section{Método}

\section{Participantes}

Participaram neste estudo 78 estudantes de Psicologia de uma universidade particular em Aracaju (Sergipe), todos brancos e com idade variando de 18 a 38 anos $(M=21,1 D P$ $=2,94$ ), sendo $79 \%$ do sexo feminino. A definição da cor da pele dos participantes foi feita conjuntamente pelo pesquisador e um colaborador. Foram mantidos para as análises apenas os participantes que foram avaliados consensualmente como "brancos". Isto implicou na exclusão de sete questionários, restando, portanto, 71 questionários válidos.

\section{Procedimentos}

Os participantes eram abordados em sala de aula e convidados a colaborarem em um estudo sobre a formação de impressões. O delineamento experimental utilizado foi inter-participantes do tipo 2 (performance social dos grupos: sucesso versus fracasso) por 2 (cor da pele dos grupos: negros versus brancos). A variável cor da pele foi manipulada através da apresentação de uma fotografia dos membros de cada grupo. Os 71 participantes foram distribuídos aleatoriamente pelas quatro condições experimentais.

\section{Material}

Foram utilizados dois tipos de questionários, na primeira página dos questionários constava um cenário, no qual era descrita a situação de um grupo de brasileiros que obtinha sucesso econômico e social ou que fracassava. Abaixo do cenário era reproduzida uma fotografia de três pessoas de sexo masculino com idade variando entre 22 e 27 anos, que representavam esse grupo. Em seguida, os participantes deveriam atribuir ao grupo cada uma das características naturais e culturais validadas no estudo $1 \mathrm{e}$, finalmente, deveriam indicar, numa escala tipo Likert, a cor da pele do grupo que viam na foto. Um dos modelos de questionário contava uma história sobre um grupo de pessoas com sucesso social e o outro modelo de questionário contava uma história sobre o fracasso social.

Foram utilizadas quatro fotografias, duas para representar um grupo de pessoas brancas (com e sem sucesso) e outras 
duas para representar os negros com e sem sucesso. As fotografias utilizadas para representar o grupo dos brancos eram compostas pelas mesmas pessoas, apenas a roupa dos participantes era alterada. Na condição de sucesso, os três modelos da foto usavam terno e gravata; na condição de fracasso, eles vestiam uma camisa simples. Nas fotos utilizadas para representar o grupo dos negros, adotamos o mesmo procedimento, ou seja, os modelos das duas fotos eram os mesmos, apenas a roupa mudava.

A fim de analisar a adequação das fotografias para o estudo, isto é, se não existiam, nas pessoas utilizadas como modelos nas fotos, diferenças estéticas ou de qualidade gráfica que pudessem interferir nos resultados, efetuamos um pré-teste das fotografias. Para tanto, indagamos a um grupo de 45 estudantes universitários sobre aspectos de cada uma das fotos. Cada participante avaliava apenas uma das fotos e indicava a cor da pele (a escala variava de 1, "negros" a 7 "brancos") e a aparência física das três pessoas da foto (a escala variava de 1, "má aparência física", a 7 "boa aparência física"). As fotografias utilizadas no pré-teste apresentavam todos os alvos vestindo a mesma roupa. Os resultados indicaram que não existem diferenças ao nível da percepção de aparência física dos alvos, $F(1,44)<1 n s$. Os alvos brancos são percebidos como tendo boa aparência física $(M=4,43$ $D P=1,20)$ de igual maneira para os alvos negros $(M=4,59$ $D P=1,26)$. Com relação à cor da pele, o efeito dos alvos foi significativo, $F(1,44)=141.17 p<0,0001$. Os alvos brancos são percebidos como mais "brancos" $(M=5.65 D P=1.30)$ do que os alvos negros $(M=1,68 D P=0,89)$.

\section{Resultados e Discussão}

\section{Verificação da manipulação}

Fizemos uma verificação da manipulação, através da pergunta: "Em que medida considera este grupo bem/mal sucedido social e economicamente?" A escala variava de 1 (pouco bem sucedido) a 5 (muito bem sucedido). Os resultados indicaram que os grupos com sucesso são percebidos como mais bem sucedidos $(M=3,69)$ do que os que fracassam $(M=3,05, F(1,69)=6.53 p<0,01)$.

\section{Cor da pele, performance social e infra-humanização}

Primeiramente, investigamos se haviam respostas diferenciadas entre homens e entre mulheres na amostra pesquisada. Os resultados de uma ANOVA, com medidas repetidas, indicaram que não existe efeito multivariado do gênero, $F(1,69)$ $=1.62 p=0,21$ e tampouco efeitos univariados, $F \mathrm{~s}(1,69)$ $\leq 1 n s$. Tendo verificado que o gênero dos participantes não interferiu em suas respostas, começamos a analisar os efeitos da cor da pele e da performance social na atribuição de características naturais e culturais aos grupos. Realizamos novamente uma ANOVA com medidas repetidas, tomando as duas primeiras variáveis como independentes inter-participantes e o conteúdo dos traços (naturais versus culturais) e a sua valência (positivos verssus negativos) como variáveis independentes intra-participantes. A variável dependente foi o escore de atribuição dos traços. Os resultados indicaram que não houve efeito principal da cor da pele, $F(1,67)<1$, ns.,
Tabela 2. Médias e desvios padrões (entre parêntesis) da atribuição de traços em função do conteúdo e do sucesso

\begin{tabular}{lcc}
\hline \multirow{2}{*}{ Sucesso } & \multicolumn{2}{c}{ Conteúdo dos Traços } \\
\cline { 2 - 3 } & Cultura & Natureza \\
\hline Sucesso & $1,62_{\mathrm{a}}$ & $1,44_{\mathrm{b}}$ \\
& $(0,51)$ & $(0,45)$ \\
\multirow{2}{*}{ Fracasso } & $1,16_{\mathrm{c}}$ & $1,28_{\mathrm{bc}}$ \\
& $(0,54)$ & $(0,52)$ \\
\hline
\end{tabular}

Nota: Médias com letras diferentes diferem significativamente (Student Newman-Keuls, $p<.05$ ). A escala variava de 0 (nada característico) a 4 (totalmente característico)

e nem de interação entre a cor da pele e o sucesso, $F(1,67)$ $=2.56 p=0.11$. Entretanto, o efeito principal multivariado da performance foi significativo, $F(1,67)=9.27 p<0,01$. São atribuídas mais características aos grupos com sucesso $(M=1,53)$ do que aos que fracassam $(M=1,22)$.

Ao nível dos efeitos univariados, não houve efeito principal do conteúdo dos traços, $F(1,67)<1$, ns. E, contra o esperado, não houve interação entre conteúdo e cor da pele, $F(1,67)<1, n s$. Entretanto, confirma-se a nossa hipótese referente à interação entre perfomance social e conteúdo dos traços, $F(1,67)=5.71, p<0,05$. Como podemos ver na Tabela 2, a média de atribuição dos traços de cultura para os grupos com sucesso é maior do que a média de atribuição dos traços de natureza. A atribuição de traços de cultura é também maior para os grupos que obtêm sucesso do que para os que fracassam, não havendo diferenças ao nível dos traços de natureza. Este resultado é importante porque demonstra que a atribuição diferenciada de traços de cultura é um indicador de inferiorização e infra-humanização dos grupos. Embora sem o efeito hipotetizado da cor da pele.

A interação entre conteúdo dos traços, sucesso e cor da pele dos grupos não foi significativa, $F(1,67)=1.74$ $p=0,19$. Com relação aos efeitos da valência, verificamos um efeito principal, $F(1,67)=48.31 p<0,0001$, que indica que a atribuição de traços positivos é maior $(M=1,78)$ do que a de traços negativos $(M=0,97)$. Verificamos que este efeito é qualificado por uma interação entre valência e performance, $F(1,67)=36.38 p<0,0001$. Ocorre uma maior atribuição de traços positivos para os grupos que obtêm sucesso $(M=2,29)$ do que para os grupos que fracassam $(M=1,27)$. Ao nível dos traços negativos, verifica-se que estes são mais atribuídos para os grupos que fracassam $(M=1,16)$ do que aos que obtêm sucesso $(M=0,77)$. Os grupos que fracassam não são diferenciados em termos de traços positivos e negativos.

Tabela 3. Médias e desvios padrões (entre parêntesis) da atribuição de traços em função da valência, do conteúdo e do sucesso.

\begin{tabular}{lcccc}
\hline \multirow{2}{*}{ Valência } & \multicolumn{2}{c}{ Traços culturais } & \multicolumn{2}{c}{ Traços naturais } \\
\cline { 2 - 5 } & Sucesso & Fracasso & Sucesso & Fracasso \\
\hline Positivos & $2,47_{\mathrm{a}}$ & $1,17_{\mathrm{c}}$ & $2,11_{\mathrm{d}}$ & $1,37_{\mathrm{c}}$ \\
& $(0,93)$ & $(0,70)$ & $(0,77)$ & $(0,71)$ \\
\multirow{2}{*}{ Negativos } & $0,76_{\mathrm{b}}$ & $1,14_{\mathrm{c}}$ & $0,78_{\mathrm{b}}$ & $1,19_{\mathrm{c}}$ \\
& $(0,66)$ & $(0,80)$ & $(0,51)$ & $(0,85)$ \\
\hline
\end{tabular}

Nota: Médias com letras diferentes diferem significativamente (Student Newman-Keuls, $p<.05)$. 
Verificamos ainda uma interação tripla entre valência, performance e conteúdo, $F(1,67)=4.69 p<0,05$, que qualifica a anterior. Como podemos ver na Tabela 3, o efeito de uma maior atribuição de traços culturais do que naturais, para os grupos com sucesso, verifica-se apenas ao nível dos traços positivos. Os grupos que fracassam recebem, de maneira indiferenciada, traços naturais e culturais, positivos e negativos. Já os grupos que obtêm sucesso recebem mais traços culturais positivos do que naturais positivos e não são diferenciados ao nível dos traços culturais e naturais negativos.

A interação entre valência dos traços, performance e cor da pele dos grupos não foi encontrada, $F(1,67)<1 n s$. A interação entre conteúdo e valência dos traços com a cor da pele dos grupos também não foi verificada, $F(1,67)<1$ ns. O mesmo ocorreu para a interação quádrupla (conteúdo, valência, cor da pele e "performance"), $F(1,67)<1 \mathrm{~ns}$.

Estes resultados, no seu conjunto, indicaram que as nossas hipóteses sobre o efeito da cor da pele e da "performance" na infra-humanização dos negros foram apenas parcialmente confirmadas. A nossa primeira hipótese era a de que os negros seriam menos caracterizados em termos de traços de cultura do que os brancos. Os resultados indicaram que o efeito da cor da pele sobre o conteúdo dos traços não foi significativo. A nossa segunda hipótese referia-se ao efeito do sucesso no conteúdo dos traços, esperávamos que os grupos com sucesso fossem mais caracterizados em termos de traços de cultura do que os grupos que fracassam. Esta hipótese foi confirmada, embora com a interferência da valência dos traços. Os resultados indicaram que uma maior atribuição de traços culturais do que naturais, para os grupos com sucesso, ocorre apenas no que se refere aos traços positivos. Este resultado parece indicar que a discriminação dos que fracassam segue um modelo que aglutina a biologização das diferenças, objetivada pela atribuição de menos traços culturais e mais traços naturais, com a assimetria positivo/negativo, que reflete o caráter mais sutil do preconceito na atualidade (Mummendey, 1995).

\section{Efeitos do sucesso e da cor da pele sobre o branqueamento}

Para testarmos a hipótese do branqueamento como mediador dos efeitos da cor da pele e do sucesso dos grupos na

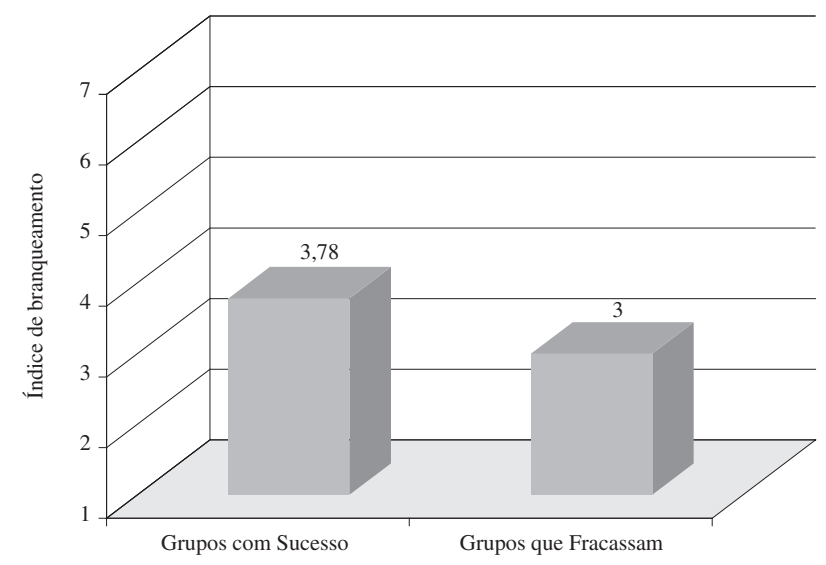

Nota: a escala variava de 1 (negro) a 7 (branco)

Figura 1. Médias de branqueamento dos grupos-alvo em função do sucesso infra-humanização, realizamos, primeiramente uma análise de variância (univariada), tomando o branqueamento como variável dependente da cor da pele objetiva dos grupos e da sua "performance" social. Os resultados indicaram um efeito principal da cor da pele dos grupos, $F(1,70)$ $=61.15 p=0,0001$. Os negros são percebidos como menos brancos $(M=2,17 D P=1,59)$ do que os brancos $(M=4.66$ $D P=1,11)$. Não houve interação entre a cor percebida e a performance, $F(1,70)<1 n s$. Entretanto, e em consonância com as nossas hipóteses, verificamos um efeito principal da "performance" no "branqueamento", $F(1,70)=5.41 p=0,02$. Como podemos ver na Figura 1, os grupos que obtêm sucesso são vistos como "mais brancos" do que os que fracassam, que são "enegrecidos".

Tendo verificado que a percepção da cor da pele dos grupos é moderada pela "performance" social e econômica dos grupos, podemos supor que os efeitos da cor da pele percebida dos grupos na sua infra-humanização, podem ser mediados pelo branqueamento. De tal modo que, em algumas formas de expressão do racismo brasileiro, o branqueamento pode ser usado como uma variável mediadora entre a cor da pele percebida, o sucesso dos grupos e a infra-humanização.

A fim de testar esta hipótese, seguimos os procedimentos sugeridos por Baron e Kenny (1986). De acordo com estes autores, uma das formas de analisar a mediação é realizando um conjunto de regressões múltiplas. O efeito de mediação ocorre quando são satisfeitas as seguintes condições: (1) existe um efeito da variável independente (VI) sobre a variável dependente (VD); (2) existe um efeito da VI sobre a variável mediadora (VM); (3) existe um efeito significativo da VM sobre a VD e, finalmente (4) o efeito da VI sobre a VD torna-se mais fraco, ou mesmo desaparece, quando a variável mediadora é colocada no modelo de análise. Quando o efeito da variável independente desaparece, depois do controle da variável mediadora, estamos diante de uma mediação perfeita. Para testar o efeito de mediação do branqueamento, conduzimos alguns conjuntos de análises de regressão, utilizando o método stepwise. Num primeiro conjunto de análises, regredimos os efeitos da performance sobre os indicadores de racismo. Noutra análise, regredimos o sucesso sobre o branqueamento. Num outro conjunto de análises, regredimos o branqueamento sobre os indicadores de infra-humanização. Finalmente, para verificarmos os efeitos de mediação, realizamos outro conjunto de análises de regressão, no qual analisamos os efeitos da performance sobre a infra-humanização quando o branqueamento era controlado.

Para as análises, adotamos ainda os procedimentos propostos por Mummendey, Otten, Berger e Kessler (2000), que realizam análises de mediações separadas para cada um dos níveis de uma das variáveis independentes. No caso do nosso estudo, em função das nossas hipóteses, escolhemos a cor da pele dos grupos-alvo como variável de corte. Primeiramente, testamos se o branqueamento atuava como um mediador entre os efeitos do sucesso dos brancos e a sua infra-humanização. Os resultados indicaram que, no caso dos brancos, a correlação entre "performance" e branqueamento, embora positiva, não é significativa, $r(35)=0,22 p=0,21^{6}$.

Em seguida, testamos a mediação apenas para o grupo dos negros. Os resultados indicaram um efeito de mediação 
do branqueamento na relação entre sucesso e atribuição de traços de cultura positiva. Quanto maior o sucesso dos negros, maior a atribuição de traços de cultura positivos, $\beta=0.62, F(1,35)=20.72 p<0,001$ (ver Figura 2). Também verificamos um efeito do branqueamento sobre a atribuição de traços de cultura positivos, $\beta=0,48, F(1,35)=10.26$ $p<0,01$, quanto mais os negros são percebidos como brancos, mais lhes são atribuídos traços de cultura positivos. Entretanto, quando regredimos o branqueamento e o sucesso sobre a atribuição dos traços de cultura positivos, verificamos que o efeito do branqueamento permanece significativo, $\beta=0,32, F(1,35)=5.65 p<0,05$, mas o efeito direto do sucesso torna-se mais fraco, $\beta=0,51 F(1,35)=14.74$ $p<0,01$. Na primeira regressão, a variável independente explica $36 \%$ da variância da variável dependente $\left(R^{2}=0,36\right)$, quando introduzimos o mediador, o nível de explicação sobe consideravelmente $\left(R^{2}=0,44\right)$. Assim, os traços de cultura positivos são atribuídos predominantemente aos negros com sucesso que são branqueados. De outra maneira, o branqueamento é uma condição necessária para a atribuição de traços de cultura positivos aos negros com sucesso.

Não houve efeito de mediação do branqueamento em relação às outras dimensões de traços de natureza e cultura. Entretanto, verificamos uma mediação perfeita do

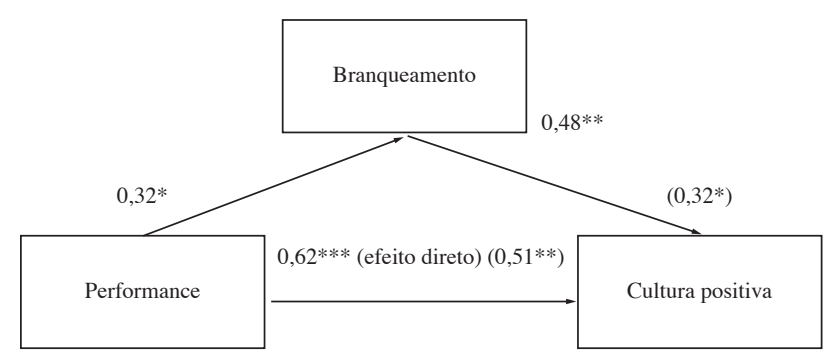

$* p<0,05 ; * * p<0, .01 ; * * * p<0,001$

Figura 2. Análise de mediação do sucesso como preditor, o branqueamento como mediador e a representação dos grupos em termos de traços de cultura positiva como variável dependente $(\mathrm{N}=35)$

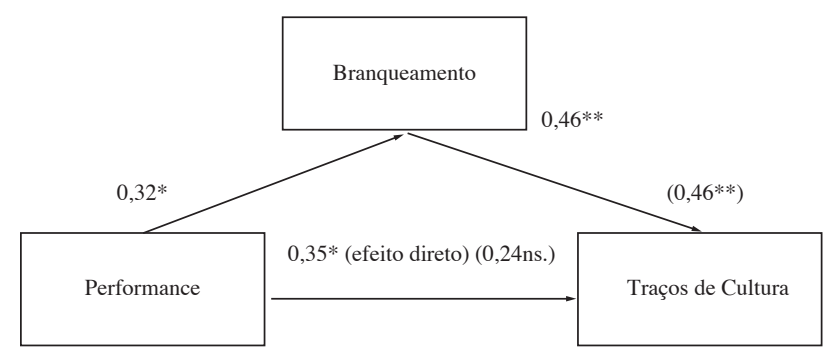

$* p<0,05 ; * * p<0,01$

Nota: performance 0 (fracasso) 1 (sucesso).

Figura 3. Análise de mediação do sucesso como preditor, o branqueamento como mediador e a caracterização dos negros em termos de traços de cultura como variável dependente $(\mathrm{N}=35)$

6 A performance foi transformada numa variável dummy e variou de 0 (fracasso) a 1 (sucesso). O branqueamento variava de 1 (negro) a 7 (branco). branqueamento nos efeitos do sucesso sobre a dimensão compósita da cultura (traços de cultura positivos + traços de cultura negativos). Existe um efeito direto do sucesso sobre a caracterização dos negros em termos culturais, $\beta=0,35$ $F(1,35)=4.78 p<0,05$. Aos negros com sucesso são atribuídos mais traços culturais (ver Figura 3). Também o efeito do branqueamento é significativo, $\beta=0,46 F(1,35)=9.14$ $p<0,01$, quanto maior o branqueamento maior a caracterização cultural dos negros. Entretanto, o efeito direto do sucesso desaparece quando controlamos o efeito do branqueamento, $\beta=0,24 F(1,35)=2.07 p=0,16$, ao passo que o efeito do branqueamento mantém-se inalterado, $\beta=0,46, F(1,35)=$ $9.14 p<0,01$. Sendo assim, a atribuição de traços culturais aos negros ocorre apenas quando os negros são branqueados. O contrário também é verdadeiro, quanto mais os negros que fracassam são enegrecidos, menos características culturais lhes são atribuídas. A mediação do branqueamento também aumenta o poder preditivo das variáveis, na primeira regressão (sem o mediador) a variância explicada é de $10 \%$ $\left(R^{2}=0,10\right)$, ao passo que, quando introduzimos o mediador na equação de regressão, a variância explicada sobe para $19 \%\left(R^{2}=0,19\right)$.

Também analisamos a mediação do branqueamento sobre a atribuição de características positivas e negativas aos grupos. A atribuição dos traços positivos aos grupos foi mediada pelo branqueamento. Verifica-se um efeito direto do sucesso sobre a atribuição de traços positivos, $\beta=0,58, F(1,35)=$ $17.43 p<0,001$, quanto maior o sucesso mais traços positivos. Também o efeito do branqueamento sobre a atribuição de traços positivos foi significativo, $\beta=0,49, F(1,35)=10.71$ $p<0,01$, quanto mais os negros são percebidos como brancos, mais traços positivos lhes são atribuídos. Contudo, o efeito direto do sucesso se torna mais fraco quando controlamos o branqueamento, $\beta=0,47 F(1,35)=11.97 p<0,01$. Quanto maior o branqueamento dos negros que obtêm sucesso, mais traços positivos lhes são atribuídos, ou ainda, quanto mais os negros que fracassam são percebidos como negros, menor a atribuição de traços positivos (ver Figura 4). O mediador, neste caso, implica um aumento da variância explicada de $32 \%\left(R^{2}=0,32\right)$ para $41 \%\left(R^{2}=0,41\right)$.

\section{Considerações finais}

Consideramos que o indicador de infra-humanização proposto nessa investigação possui pelos menos duas vantagens em relação a outras medidas de racismo. A primeira delas é

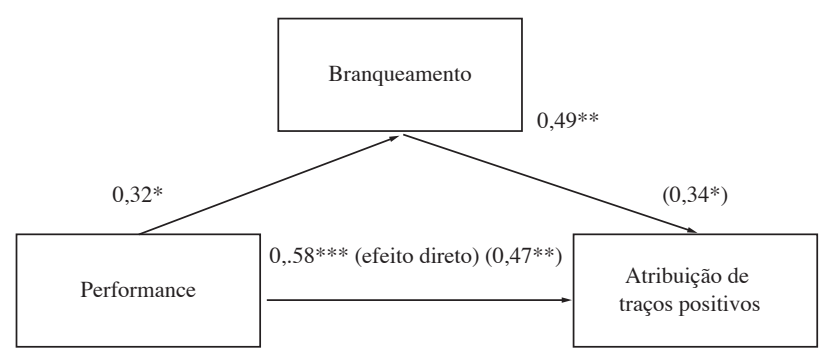

$* p<0,05 ; * * p<0,01 ; * * * p<0,001$

Nota: performance 0 (fracasso) 1 (sucesso).

Figura 4. Análise de mediação do sucesso como preditor, o branqueamento como mediador e a positividade dos grupos como variável dependente $(N=35)$ 
que se trata de um indicador não obstrutivo das respostas; uma vez que os participantes quando respondem não percebem que respostas mais "naturalizadoras" são também respostas mais racistas. Uma segunda vantagem desse indicador no estudo do racismo é o conteúdo avaliado. Como se trata de uma forma de representação social "naturalizadora" dos grupos, temos um indicador de racismo com muita validade interna, uma vez que o racismo, como refere Delacampagne (1990), existe sempre que se tenta explicar uma condição social e cultural por meio de uma característica natural. Este fato torna este indicador diferente de outras escalas utilizadas, que abordam apenas elementos relacionados com a discriminação (Kinder \& Sears, 1981; McConahay, 1986).

Todavia, os resultados obtidos neste estudo indicaram que o indicador de infra-humanização só teve efeito através da mediação do branqueamento. De modo que, este tipo de indicador comprovadamente eficaz em estudos sobre racismo na Europa (Lima \& Vala, 2002; Moscovici \& Pérez, 1999), pode não ser tão eficaz no estudo do racismo numa sociedade na qual negros e brancos apresentam-se, pelo menos ao nível formal, integrados culturalmente.

Neste estudo, os traços de cultura foram efetivos através da mediação do branqueamento. Os negros com sucesso são descritos em termos de traços de cultura quando são branqueados. Este padrão de resultados confirma os nossos pressupostos teóricos de que cada contexto de relações "racializadas" possui uma forma específica de racismo, que apresenta manifestações particulares. Diferentemente da Europa, onde os grupos vítimas de racismo (imigrantes) são percebidos como exógenos àquela formação cultural, no Brasil brancos e negros são todos brasileiros, ainda que não tenham direito igual à cidadania. De modo que, o racismo "à brasileira" possui especificidades. Graças ao notável caleidoscópio de cores que compõem a sociedade brasileira, desenvolve-se uma forma de representação que associa o fracasso à cor negra e o sucesso à cor branca, e que pode mudar subjetivamente a cor de um indivíduo, a fim de manter intactas as crenças coletivas e as atitudes negativas associadas à categoria de pertença desse indivíduo. Neste sentido, o branqueamento dos negros bem sucedidos permite que os participantes brancos realizem uma maior atribuição de traços positivos na descrição deste grupo e que lhes atribua mais traços de cultura.

A literatura sobre as novas expressões do racismo tem demonstrado que a dimensão dos traços positivos é a mais importante nas expressões mais veladas de racismo, uma vez que, na atualidade, o racismo se expressa mais pela negação dos traços positivos do que pela atribuição de traços negativos aos grupos minoritários (Gaertner \& McLaughlin, 1983; Pettigrew \& Meertens, 1995; Vala \& cols., 1999). Estes resultados nos permitem ainda dizer que negros são percebidos positivamente porque e, apenas porque, são branqueados.

Ao nível da atribuição de traços de cultura, vimos que os negros são “culturalizados” apenas quando são branqueados. Este resultado demonstra um processo de infra-humanização dos negros que reflete, ainda hoje, as ideologias do racismo científico do século XIX, aquelas mesmas que motivaram as políticas de imigração de mão-de-obra européia para o Brasil, depois da abolição da escravidão. Naquele período, acreditava-se que o Brasil só se tornaria um país civilizado e desenvolvido se, ao longo do tempo, branqueasse a sua população, extirpando o "sangue negro". Parece que, quase dois séculos depois, ainda se acredita que a civilidade e o desenvolvimento das pessoas só é possível quando elas são percebidas como brancas.

Embora os nossos dados decorram de um estudo experimental, com uma amostra reduzida e localizada em um contexto específico e particular de relações "racializadas" no Brasil, podemos supor, amparados por alguma evidência empírica (Adorno, 1996; França \& Monteiro, 2002; Harris, Consorte, Lang \& Byrne, 1993; Lima, 2003) e evidências teóricas (Alencastro, 1998; Degler, 1971; Guimarães, 1999, Harris, 1970; Piza, 2000; Schwarcz, 1993; Skidmore, 1989), que de uma maneira geral, no Brasil, o branqueamento desempenha um papel fundamental no racismo, de tal modo que esta também pode ser uma variável mediadora fundamental das percepções e avaliações dos negros em outros contextos de relações "racializadas" no Brasil.

Assim, podemos considerar que estes resultados sinalizam para a importância de outras análises empíricas que explorem e aprofundem o caráter mediador que o branqueamento exerce nas expressões de racismo, inclusive comparando outras cidades e regiões do Brasil, com diferentes composições etnográficas, para se verificar se existem diferenças regionais nas formas de expressão do racismo.

\section{Referências}

Adorno, S. (1996). Violência e racismo: Discriminação no acesso à justiça penal. Em L.M. Schwarcz \& R. da S. Queiroz (Orgs.), Raça e diversidade (pp. 255-275). São Paulo: EDUSP.

Alencastro, L.F. de (1998). Vida privada e ordem privada no Império. Em L.F. de Alencastro (Org.), História da vida privada no Brasil Império: A corte e a modernidade nacional, Vol. 2, (pp. 11-94). São Paulo: Companhia das Letras.

Baron, R.M. \& Kenny, D.A. (1986). The moderator-mediator variable distinction in social psychological research: Conceptual, strategic, and statistical considerations. Journal of Personality and Social Psychology, 51(6), 1173-1182.

Bar-Tal, D. (1989). Group beliefs: A conception for analyzing group structure, processes, and behavior. New York: SpringerVerlag.

Camino, L., Silva, P., Machado, A. \& Pereira, C. (2001). A face oculta do racismo no Brasil: Uma análise psicossociológica. Revista de Psicologia Política, 1(1), 13-36.

Correia, I., Brito, R., Vala, J. \& Perez, J. (2001). Normes antiracistes et persistance du racisme flagrant: Analyse comparative des attitudes face aux Tziganes et face aux noirs au Portugal. Manuscrito não publicado. Centro de Investigação e Intervenção Social do ISCTE, Lisboa.

Degler, C.N. (1971). Nem preto nem branco: Escravidão e relações raciais no Brasil e nos Estados Unidos. Rio de Janeiro: Labor.

Delacampagne, C. (1990). Racism in the West: From praxis to logos. Em D.T. Goldberg (Org.), Anatomy of racism. Minneapolis: University of Minnesota Press.

Fernandes, F. (1966). O negro no mundo dos brancos. São Paulo: Difusão Européia do Livro.

França, D.X. \& Monteiro, M.B. (2002). Identidade racial e preferência em crianças brasileiras de 5 a 10 anos. Psicologia, 16(2). 
Freyre, G. (1933/1983). Casa-grande e senzala: Formação da família brasileira sob o regime de economia patriarcal. Lisboa: Edição Livros do Brasil.

Gaertner, S.L. \& Dovidio, J.F. (1986). The aversive form of racism. Em J.F. Dovidio \& S.L. Gaertner (Orgs.), Prejudice, discrimination and racism: Theory and research (pp. 61-89). Orlando: Academic Press.

Gaertner, S.L. \& McLaughlin, J.P. (1983). Racial stereotypes: Associations and ascriptions of positive and negative characteristic. Social Psychology Quarlerly, 46(1), 23-30.

Guimarães, A.S.A. (1999). Racismo e anti-racismo no Brasil. São Paulo: Editora 34.

Harris, M. (1970). Referential ambiguity in the calculus of Brazilian racial identity. Southwestern Journal of Antropology, 26(1), 1-14.

Harris, M., Consorte, J.G., Lang, J. \& Byrne, B. (1993). Who are the whites? Imposed census categories and the racial demography of Brazil. Social Forces, 72(2), 451-462.

Katz, I. \& Hass, R.G. (1988). Racial ambivalence and American value conflict: Correlational and priming studies of dual cognitive structures. Journal of Personality and Social Psychology, 55(6), 893-905.

Kinder, D.R. \& Sears, D.O. (1981). Prejudice and politics: Symbolic racism versus racial threats to the good life. Journal of Personality and Social Psychology, 40(3), 414-431.

Leyens, J.P., Paladino, P., Rodriguez-Torres, R., Vaes, J., Demoulin, S., Rodriguez-Perez, A. \& Gaunt, R. (2000). The emotional side of prejudice: The attribution of secondary emotions to ingroups and outgroups. Personality and Social Psychology Review, 2(2), 186-197.

Leyens, J.P., Rodriguez-Perez, A., Rodriguez-Torres, R., Gaunt, R., Paladino, P., Vaes, J. \& Demoulin, S. (2001). Psychological essentialism and the differential attribution of uniquely human emotions to ingroups and outgroups. European Journal of Social Psychology, 31, 395-411.

Lima, M.E.O. (2003). Normas sociais e racismo: Efeitos do individualismo meritocrático e do igualitarismo na infra-humanização dos negros. Tese de Doutorado, Instituto Superior de Ciências do Trabalho e da Empresa, Lisboa.

Lima, M.E.O. \& Vala, J. (2002). Individualismo meritocrático, diferenciação cultural e racismo. Análise Social, XXXVII, 181-207.

McConahay, J.B. (1986). Modern racism, ambivalence, and the modern racism scale. Em J.F. Dovidio \& S.L. Gaertner (Orgs.), Prejudice, discrimination, and racism (pp. 91-125). Nova York: Academic Press.

McConahay, J.B. \& Hough, J.C. Jr. (1976). Symbolic racism. Journal of Social Issues, 32(1), 23-45.

Moscovici, S. \& Pérez, J.A. (1997). Prejudice and social representations. Papers on Social Representations, 6(1), 27-36.

Moscovici, S. \& Pérez, J.A. (1999). A extraordinária resistência das minorias à pressão das maiorias: o caso dos ciganos. Em J. Vala (Org.), Novos racismos: Perspectivas comparativas (pp. 103-119). Oeiras: Celta.

Mummendey, A. (1995). Positive distinctiveness and social discrimination: An old couple living in divorce. European Journal of Social Psychology, 25(5), 657-670.

Mummendey, A., Otten, S., Berger, U. \& Kessler, T. (2000). Positive-negative asymmetry in social discrimination: Valence of evaluation and salience of categorization. Personality and Social Psychology Bulletin, 26(10), 1258-1270.

Munanga, K. (1996). As facetas de um racismo silenciado. Em L.M. Schwarcz \& R. da S. Queiroz (Orgs.), Raça e diversidade (pp. 213-229). São Paulo: EDUSP.

Pettigrew, T.F. \& Meertens, R.W. (1995). Subtle and blatant prejudice in western Europe. European Journal of Social Psychology, 25(1), 57-75.

Piza, E. (2000). Branco no Brasil? Ninguém sabe, ninguém viu. Em A.S.A. Guimarães \& L. Huntley (Orgs.), Tirando a máscara: Ensaios sobre racismo no Brasil (pp. 97-126). São Paulo: Paz e Terra.

Ribeiro, D. (1996). Sobre a mestiçagem no Brasil. Em L.M. Schwarcz \& R.S. Queiroz (Orgs.), Raça e diversidade (pp. 187-211). São Paulo: EDUSP.

Schwarcz, L. (1993). O espetáculo das raças: Cientistas, instituições e a questão racial no Brasil. São Paulo: Companhia das Letras.

Schwarcz, L.M. (1996). As teorias raciais, uma construção histórica de finais do século XX. O contexto brasileiro. Em L.M. Schwarcz \& R.S. Queiroz (Orgs.), Raça e diversidade (pp. 147-185). São Paulo: EDUSP.

Schwartz, S.H. \& Struch, N. (1989). Values, stereotypes, and intergroup antagonism. Em D. Bar-Tal, C.F. Graumann, A. Kriglanski, \& W. Stroebe (Orgs.), Stereotyping and prejudice: changing conceptions (pp. 151-167). Nova York: SpringerVerlag.

Skidmore, T. (1989). Realidades raciais e pensamento racial depois da abolição. Em T. Skidmore (Org.), Preto no branco: Raça e nacionalidade no pensamento brasileiro (pp. 55-94). Paz e Terra: São Paulo.

Struch, N. \& Schwartz, S.H. (1989). Intergroup agression: Predictors and distinctiveness from ingroup bias. Journal of Personality and Social Psychology, 56(3), 364-373.

Turra, C. \& Venturi, G. (1995). Racismo cordial: A mais completa análise sobre preconceito de cor no Brasil. São Paulo: Ática.

Vala, J., Brito, R. \& Lopes, D. (1999). Expressões dos racismos em Portugal: Perspectivas psicossociológicas. Lisboa: Editora do Instituto de Ciências Sociais da Universidade de Lisboa. 